\title{
Management as a practice: Where questioning, debate and the 'real-world' meet
}

Our last edition of JMO for 2018 rounds off a year of exploration and investigation into the depth and breadth that is management. This saw our fifth issue edited by Jawad Syed and Edwina Pio that challenges a homogenised view to delve into the richness of contextualising diversity within Islam. The theme of challenging though presenting evidence and asking for open and intelligent debate has certainly been a theme of our issue this year. This was reflected in issue 4 curated by Antoine Hermens who presented us with a selection of papers dedicated to creativity and innovation management: The complex dynamics of shaping forces. The notion of rising to challenge was a key theme in issue 3, where Timothy F O'Shannassy and Ard-Pieter de Man presented 'A research agenda for alternative forms of corporate governance' in Journal of Management \& Organization. Lastly, I began the year with two issues which laid down the challenge that good management is hard, but someone has to do it (and here are some suggestions), and leadership: What's all the fuss about (and what does all the hype really deliver)?

While presenting each of our issues as a coherent and consistent offering has been a key feature of our offerings for 2018 , it has led to the potential criticism that we may be missing the incredible depth and breadth that is management. This is not a criticism I would like to see verified. Just as our ANZAM annual conference draws in attendees from all aspects of business and management from around the world, so this last issue presents a collection of papers that I hope will not only showcase some of this diversity but also span the globe in doing so.

We begin with Jon L. Pierce, Iiro Jussila and Dahui Li who take us through the fascinating work they have undertaken to develop and validate an instrument for 'For Assessing Collective Psychological Ownership in Organizational Field Settings'. While the idea of a collective psychological ownership is a very new idea in the management space, the authors suggest their measurement tool offers real potential to provide insight and explanation to a range of collective, work-related attitudes and actions. If the readability and calibre of this paper is any guide, this may very well be a tool we see being used in workplaces before too long!

The link between theoretical and practical implications for research are very much at the forefront of our second paper. Here Stephen Croucher, Cheng Zeng, Diyako Rahmani and Xuejun Cui examine 'The Relationship between Organizational Dissent and Workplace Freedom of Speech'. The study is based in Singapore. While they find that articulated dissent and latent dissent were positively correlated with workplace freedom of speech, an individuals' nation of birth influenced articulated and latent dissent - but not on workplace freedom of speech. In a world of increasingly global labour mobility, a paper had me questioning how much country of birth may continue to influence an individual's willingness to express dissent.

The connection between the wider world and what happens in the workplace takes on a very different perspective in our third paper. Here, author Heejoon Park documents a 'natural experiment' in an examination of the 'Institutionalization of Athletic Conferences for Wage Comparison in Collective Bargaining in High Schools in the US'. While most readers will be well aware of the role that social comparison plays in collective bargaining, and that our own self- 
serving bias means we are rarely able to agree on appropriate referents, in this paper Park provides us with a group who do agree. The microcosm of Wisconsin teachers' and their consensus on an appropriate comparison as the schools' athletic conferences allows for an examination of the role of technical factors and institutional theory. What the study finds is realignment to another conference saw a change in comparison groups - thus providing support for institutional theory.

Moving next to Canada for our fourth paper, Doruk Uysal Irak and Janet Mantler investigate the 'Role of Temporal Flexibility on Person-Environment Fit and Job Satisfaction'. While the structural equation modelling results are interesting (they find that temporal flexibility was directly related to increased job satisfaction and indirectly related to job satisfaction through supplementary fit, demands-abilities fit and needs-supplies fit), it is the further insights they develop that really add wider audience interest. The authors suggest that their research adds support to claims that providing employees with more control over their work schedule increases their perceptions of autonomy - a core psychological need. This adds weight to the notions that organisations who do this are likely to benefit from a satisfied and committed workforce who will also remain because they see themselves as being a good fit with their employer.

Martin Spraggon and Virginia Bodolica explicitly deal with the relationship between theory and practice in the paper titled 'A Practice-Based Framework for Understanding (Informal) Play as Practice Phenomena in Organizations'. The authors move from standard notions of 'serious play' to examine the notion of informal play to present an employee rather than a managerial perspective. The authors draw on an array of literature to provide five practice-based constructs that are developed into an integrative framework. It is a framework that both reveals and highlights key relationships to show the role of informal play - the generation of productive outcomes or as a means of more cynically resisting authority being two of the contracting (and rather delightful) insights provided.

Moving from the world of play to that of innovation, authors Ben Nanfeng Luo, Steven Lui, Chih-Hsing Liu and Rongrong Zhang provide us with a journey of 'Knowledge Exploration and Innovation: A Review and an Inverse S-Curve Proposition'. While back to a more traditionally academic paper than the last few in this issue, one also continues the theme of challenge. The recombination provided in their search framework of innovation allows them to present a reconceptualisation of our understanding of knowledge exploration on innovation. The authors suggest that their new framework allows for a specific focus as to the evolution of the benefits and costs of knowledge exploration - and perhaps most importantly sees them propose an inverse S-curve proposition of the link between knowledge exploration and innovation. The paper quickly moves from the world of theory to see a practical application - with case examples from IBM and Procter \& Gamble as the test organisations used to illustrate the new proposition.

An implicit theme in many of the papers in this issue has been that of perceived justice or fairness in the workplace. This theme is addressed directly in the last paper of our issue. Here authors Yina Mao, Chi-Sum Wong, Xiangnan Tao, Chunyan Jiang look at 'The Impact of Affect on Organizational Justice Perceptions: A Test of the Affect Infusion Model'. While this is perhaps the most theoretically grounded of all the papers in this issue, it is also one that I hope will be of interest to many, as it draws on and compares a student sample and an employee sample. It is an interesting choice in a world where student samples are often being increasingly discouraged and it shows that there can be real value in talking to and studying our students! The question the authors are looking at is well known, how do individuals form justice perceptions? Departing from the traditional notion of organisational justice because of deliberate cognitive processes, this study examines the role of affect in forming justice perceptions. Adding in two moderating contextual factors - personal relevance and group context - the results confirmed the standard finding that individuals with positive affective states perceive higher distributive and procedural justice than those in negative affective states, but they also found that personal relevance moderates the relationships. 
The seven papers presented in this sixth and last issue of JMO for 2018 move us from the domains of psychology to sociology and industrial relations, from notions of ownership and dissent to innovation and justice. We have also traversed the globe in terms of both the national settings of the research presented to the countries of the authors. While the discipline or national perspectives have produced insights into important differences, a key contribution of presenting them in this issue is that the similarities lie in the valuable contribution each can make to the worlds of academia and to practice.

Tui McKeown

Editor in Chief, JMO

Cite this article: Mckeown T. 2018. Management as a practice: Where questioning, debate and the 'real-world' meet. Journal of Management \& Organization 24: 773-775. doi:10.1017/jmo.2018.70 